\title{
Eye acupuncture for pain conditions: a scoping review of clinical studies
}

\author{
Yuan Chi', Jürgen Barth², Mei Wang ${ }^{3}$, Nicola Robinson ${ }^{1,4}$, Zan-Hua Li ${ }^{5}$ and Jian-Ping Liu, ${ }^{1,6^{*}}$ (D
}

\begin{abstract}
Background: Chinese eye acupuncture, focuses on treating different diseases by applying needle stimulation around the orbit of the eye. Since 1970, it has been used in China for the management of pain-related disorders. This scoping review systematically collected clinical studies on the use of eye acupuncture to treat pain conditions and identify any adverse events.

Methods: Six databases including PubMed, the Cochrane Library, CNKI, VIP, Wan Fang Data and SinoMed were searched from 1970 to March 2019. Randomized controlled trials (RCTs), clinical controlled trials (CCTs) and case series on eye-acupuncture for pain conditions meeting the inclusion criteria were identified. Data were extracted on patients, interventions, details of eye acupuncture, control treatments and outcomes.

Results: Searches identified 81 clinical studies and a trend demonstrating an increasing number of published studies. All studies were conducted in China and published in Chinese. These included, 45 (55.6\%) RCTs, 5 (6.2\%) CCTs, and 31 (38.3\%) case series, treating 7113 patients with 44 different pain-related diseases or symptoms. The most frequently reported conditions were headache $(18,16.2 \%)$, acute lumbar pain $(7,6.3 \%)$ and lumbar disc herniation $(7,6.3 \%)$. Treatment using small needles $(\varphi 0.25 \times 13 \mathrm{~mm})$, retained $\leq 30 \mathrm{~min}$, needling the horizontal outer orbital edge and the avoidance of manipulation during treatment were the most frequent descriptions of the interventions used. Eye acupuncture was used alone in about half of the studies and of the remaining studies it was combined with other treatment. All studies suggested some beneficial effects including: pain relief, improved quality of life and mental health, and 18 (22.2\%) adverse events.
\end{abstract}

Conclusion: Eye acupuncture, predominantly studied in China, may be a promising intervention for managing diverse pain conditions. However, given the variety of study designs and reported treatment outcomes, conclusions about the evidence for eye acupuncture for specific conditions are not possible at this stage.

Keywords: Pain relief, Traditional Chinese medicine, Eye acupuncture, Clinical studies, Scoping review

\section{Background}

For pain management, both the 2016 Centers for Disease Control and Prevention (CDC) guideline [1] and the 2017 Canadian Guideline for Opioid for Chronic

\footnotetext{
* Correspondence: jianping_|@hotmail.com

${ }^{1}$ Centre for Evidence-Based Chinese Medicine, Beijing University of Chinese Medicine, 11 Bei San Huan Dong Lu, Chaoyang District, Beijing 100029, China

${ }^{6}$ Institute of Integrated Traditional Chinese Medicine and Western Medicine, Guangzhou Medical University, Guangzhou, China

Full list of author information is available at the end of the article
}

Non-Cancer Pain [2] recommended non-opioid pharmacotherapy and non-pharmacologic therapy. The role of opioids in the treatment of chronic pain has increasingly come into question due to the risk of addiction, brain damage and overdose-induced death [3-6] and has insufficient evidence on its benefits [2, 7]. Nonpharmacotherapy options to treat chronic pain include: patient education, cognitive-behavior therapy and complementary and alternative therapies [8]. Body acupuncture, as part of Traditional Chinese Medicine (TCM), has become increasingly used for pain relief worldwide

\section{BMC}

(c) The Author(s). 2021 Open Access This article is licensed under a Creative Commons Attribution 4.0 International License, which permits use, sharing, adaptation, distribution and reproduction in any medium or format, as long as you give appropriate credit to the original author(s) and the source, provide a link to the Creative Commons licence, and indicate if changes were made. The images or other third party material in this article are included in the article's Creative Commons licence, unless indicated otherwise in a credit line to the material. If material is not included in the article's Creative Commons licence and your intended use is not permitted by statutory regulation or exceeds the permitted use, you will need to obtain permission directly from the copyright holder. To view a copy of this licence, visit http://creativecommons.org/licenses/by/4.0/ The Creative Commons Public Domain Dedication waiver (http://creativecommons.org/publicdomain/zero/1.0/) applies to the data made available in this article, unless otherwise stated in a credit line to the data. 
$[9,10]$, given its beneficial effects for treating pain and disability [11] and provides a potential opportunity for integration into patient-centered care [12].

Eye acupuncture is an understudied intervention and involves fine-needle acupuncture, and may also include embedding catgut at acupoints and acupressure applied around the orbit of the eye [13]. Based on the TCM theory of the relationship of the eyes to the brain, viscera, and meridians [14, 15], this therapy originated in Liaoning province, China and was developed by an acupuncturist Jing-Shan Peng in 1970 [16]. Clinical practice, clinical experimental and observational studies $[17,18]$ and animal experiments [19-22] have demonstrated possible mechanisms in regulating the nervous system, blood measures and molecular-level expression.

Eye acupuncture is much less complicated compared to traditional body-acupuncture as it only employs 13 acupoints, namely lung, large intestine, kidney, bladder, upper jiao, liver, gallbladder, middle jiao, heart, small intestine, spleen, stomach, and lower jiao [16]. Except for the three acupoints that represent the regions of the body (upper jiao, regions above the horizontal line on the diaphragm, included upper limbs; lower jiao, regions below the horizontal line on umbilicus; and middle jiao, the remainder), the remaining ten acupoints are all named according to the related viscera. These 13 acupoints are located at $2 \mathrm{~mm}$ from the outer side of the orbit in the eight areas divided equally by four pupil-centered lines. An additional figure presents the location of the $13 \mathrm{acu}$ points (see Additional File 1). A previous anatomical study has demonstrated that eye acupuncture needles are inserted through the skin, superficial fascia, deep fascia to reach orbicularis oculi muscle (avoid touching the periosteum). The superficial fascia underneath each acupoint area is in somatosensory nerves and the vascular network is enclosed by visceral sensory nerve endings [23].

A scoping review is a relatively new evidence synthesis method for identifying knowledge gaps, examining the body of associated literature, clarifying concepts or investigating the conduct of research [24]. Data can be used to inform future clinical trials in order to prioritize conditions or treatment regimens. Scoping reviews can also be precursors to conducting systematic review and therefore may be an appropriate approach to explore existing evidence for eye acupuncture and its use in reducing pain.

The aim of this scoping review was to identify clinical studies and reports on eye acupuncture with the aim of informing practitioners, patients and researchers about the use of this emerging intervention for pain relief.

\section{Methods}

\section{Eligibility criteria}

This scoping review used the Preferred Reporting Items for Systematic Reviews and Meta-Analyses (PRISMA) and the PRISMA Extension for Scoping Reviews (PRIS MA-ScR) guidelines [25, 26].

\section{Types of studies}

Relevant clinical studies included randomized controlled trials (RCTs), controlled clinical trials (CCTs) and case series, regardless of language, publication form or publication status were identified. Case reports which could supply any additional valuable information were also collected and are reported in the appendix but were not included in the overall analysis.

\section{Types of patients}

Patients with any pain-related diseases/symptoms were eligible. Both primary and associated symptoms were included. Studies were omitted if they failed to mention patients' pain symptoms even though the disease might involve pain.

\section{Types of interventions}

Experimental interventions involving needle insertion, laser stimulation or transcutaneous electrical stimulation at the 13 acupoints, described as eye acupuncture, were eligible. Studies applying eye acupuncture therapy alone or in combination with other treatment were all considered eligible. For RCTs and CCTs, all types of control interventions were eligible.

\section{Types of outcome measures}

Studies were included if they reported outcomes of any pain-related symptom as either a primary or a secondary symptom.

\section{Literature search}

Two English and four Chinese electronic databases were searched from 1970 or from their inception through to 9 March 2019. An additional file provides the complete search strategy and results for the English database PubMed and the Chinese database CNKI (see Additional File 2).

Databases were:

- PubMed (http://www.ncbi.nlm.nih.gov/pubmed/) (1970 to 2019)

- The Cochrane Library (Issue 3, 2019) (http://www. cochranelibrary.com/)

- China Network Knowledge Infrastructure (CNKI) (http://www.cnki.net/) (1970 to 2019)

- Chinese Scientific Journals Database (VIP) (http:// www.cqvip.com/) (1989 to 2019) 
- Wan Fang data (http://www.wanfangdata.com.cn/ index.html) (1985 to 2019)

- SinoMed (http://www.sinomed.ac.cn/) (1978 to 2019)

The reference lists of included studies were scrutinized to identify possible additional relevant studies.

One author (YC) first screened titles and abstracts using NoteExpress 3.2.0.7103. Potentially eligible articles were then read in full by $\mathrm{YC}$ to determine whether they met the eligibility criteria.

\section{Data extraction and analysis}

One author (YC) extracted the data into a pre-designed electronic form using Microsoft Excel 2016 and crosschecked the data for duplications.

We designed our data extraction form followed the PRISMA and the PICO framework [27]. The extracted information included bibliometric data (published year, reference type, origin, funding, published language, journal, study type), patients (sample size, gender, age, disease/symptom), interventions (acupoints, comparisons, characteristics of needles and operations) and outcomes (symptom reduction, pain scales, adverse events, follow up).

These data were then analyzed descriptively by calculating frequencies, and percentages. Graphical representations of the data were created in Microsoft Excel 2016 and Microsoft Power BI. The flowchart was created using Microsoft Visio 2016. All the figures were imported in and processed via Adobe Photoshop (CC 2017).

\section{Results}

\section{Literature search}

A total of 940 records were retrieved from the literature search. Any duplicates were excluded, and the remaining studies were assessed for eligibility. The flowchart shows the selection process (Fig. 1). The review was conducted on 81 full-text articles [28-108]. Additionally, 30 related case reports were identified, but this information is presented in an additional file (see Additional File 3).

\section{Bibliometric information}

The 81 studies included 45 (55.6\%) RCTs, 5 (6.2\%) CCTs, and 31 (38.3\%) case series. There was an increasing overall trend in the number of publications year by year. An additional figure illustrates the year of publications in terms of study type (see Additional File 4), and the percentage which were RCTs. The earliest RCT [71] was published in 1995. Since 2008, RCTs have taken over as the dominant study type from case series.

The 81 analyzed studies, all conducted in China, originated from 20 different provinces. The 81 studies consisted of, 64 journal articles (79.0\%), 14 master's theses $(17.3 \%)$ and three conference papers (3.7\%). The 64 journal articles appeared in 33 different journals, with the journal of Chinese Acupuncture \& Moxibustion (9,

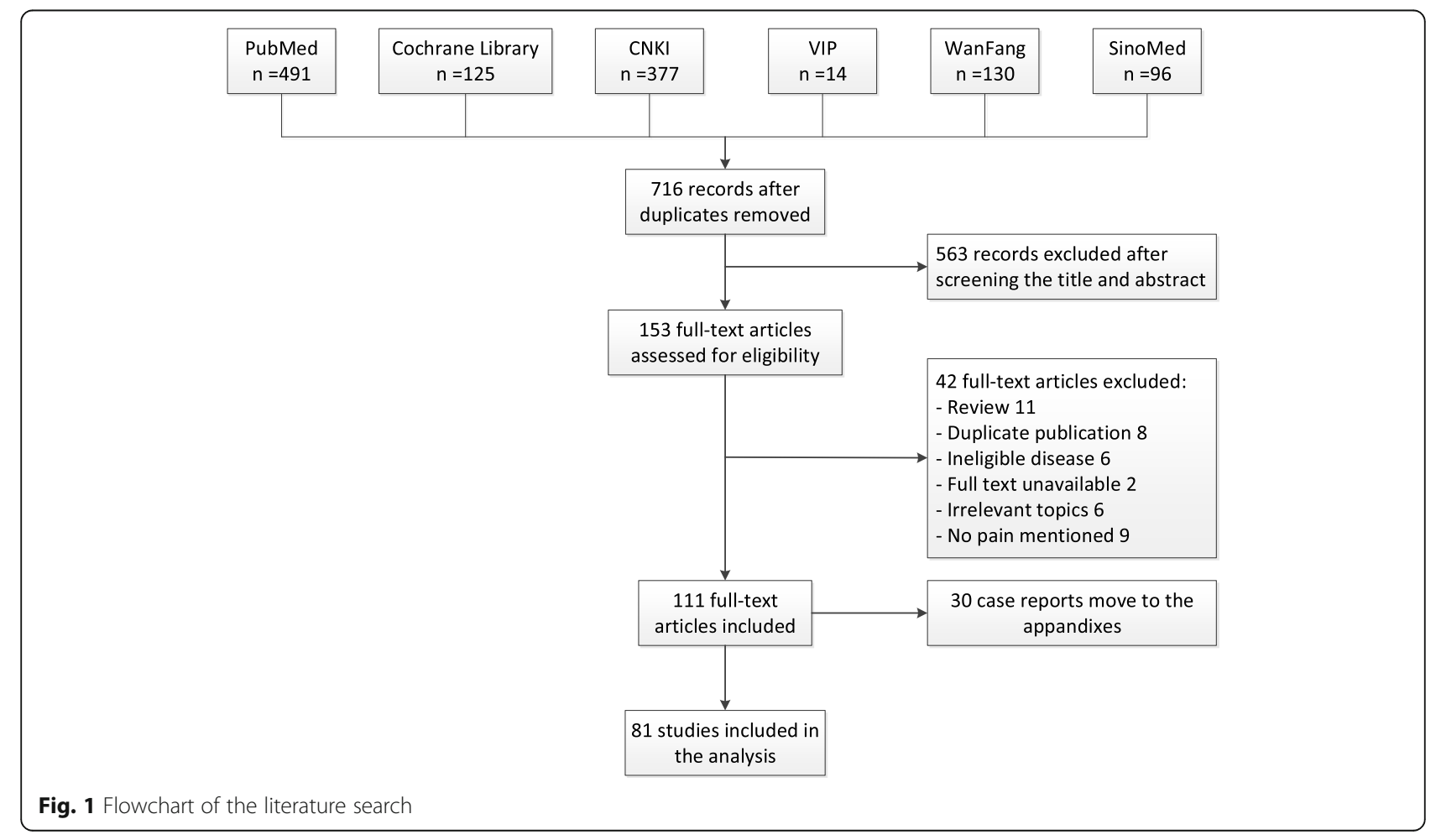


14.1\%) and the Journal of Clinical Acupuncture and Moxibustion $(8,12.5 \%)$ being the most prevalent.

\section{Patients}

In total, 7113 patients participated in the 81 studies. For trials (RCTs $n=45$ and CCTs $n=5$ ), study sample sizes ranged from 24 to 248 (median: 60; average: 84.1). Among the 81 studies, a total of $74(91.4 \%)$ studies reported gender (male: 2976, 47.6\%; female: 3272, 52.4\%) and $66(81.5 \%)$ studies reported age, with a range between 9 to 85 years. The duration of disease was reported in $60(74.1 \%)$ studies with a range of $1 \mathrm{~h}$ to 34 years. The treatment duration was reported in 59 (72.8\%) studies and ranged from 1 day to 4 months, of which, $4(6.8 \%)$ studies reported patients cured with a one-off treatment, and 56 (94.9\%) studies applied treatment within a 2 months period.

The 81 studies covered 44 different diseases/symptoms. There were 108 conditions in total as there were studies that contained more than one condition. The conditions were classified according to the International Association for the Study of Pain (IASP) Classification of Chronic Pain to the IASP's Axis 1 (regions) coding scheme for chronic pain diagnoses [109] which clearly demonstrates the results obtained [Fig. 2]. Headache (18, $16.2 \%)$ was the most frequently reported, followed by acute lumbar sprain $(7,6.3 \%)$, lumbar disc herniation ( 7 , $6.3 \%)$, shoulder-hand syndrome after stroke $(5,4.5 \%)$, periarthritis of shoulder $(5,4.5 \%)$, sciatica $(5,4.5 \%)$ and dysmenorrhea (5, 4.3\%).

\section{Interventions}

\section{Selection of acupoints}

All studies reported their selection of acupoints. Their use was shown pictorially. The three most frequently used acupoints in each region of the orbit are given in Fig. 2. Details of acupoints used for each condition are shown in an additional figure (see Additional File 5).

\section{Treatments and comparators}

In terms of treatments used in the 81 studies, 44 (54.3\%) used eye acupuncture alone and the others used eye acupuncture combined with other treatments. In the 50 trials (RCTs and CCTs), 55 eye acupuncture related comparisons were reported. Details of the treatment for each comparison are shown in an additional table (see Additional File 6). The treatments were first summarized in seven categories. In a second step for each category, subgroups were displayed by the intervention in the control group. Twenty-two comparisons (40.0\%) applied eye-acupuncture alone as an intervention in the treatment group; correspondingly, non-pharmaceutical traditional Chinese therapy $(17,30.9 \%)$ and conventional



Fig. 2 Conditions and used acupoints. $m$ = frequency the acupoints used; $\%=m /$ total frequency of all the acupoints used in that condition 
medicine $(14,25.5 \%)$ were the most commonly used control treatments.

\section{Characteristics of the needles}

Of the 81 studies, 68 (84.0\%) referred to the characteristics of acupuncture needle used, including brand/material $(39,48.1 \%)$, length $(64,79.1 \%)$ and diameter (55, 67.9\%). The details of needle size are shown in (Fig. 3). It is important to mention that since the measuring unit of acupuncture needle varies, such as cun or fen for length and hao for diameter, a conversion has been done to generalize the parameters in millimeter $(\mathrm{mm})$. The most frequently used needles were stainless steel acupuncture needles in $\phi 0.25 \mathrm{~mm} \times 13 \mathrm{~mm}$.

\section{Needling techniques}

The basic techniques of eye-acupuncture needling varied between studies. A total of 78 studies mentioned the needle retention time, ranging from "not retaining the needle" to $8 \mathrm{~h}$, with $30 \mathrm{~min}$ (21 studies, $26.9 \%$ ) being the most frequently used duration. Of the 69 studies (85.2\%) that described the approach to needle insertion, 54 studies (78.3\%) used 'horizontal needling outer orbital edge', 27 studies (39.1\%) used 'straight needling inner orbital edge', and 17 studies (24.6\%) used both simultaneously. Of the 66 studies $(81.5 \%)$ that mentioned whether the needle was manipulated or not, 47 studies $(71.2 \%)$ made it explicit not to exert any manipulation of the needle during the treatment. Two studies did not specify the kind of manipulation. For the remaining 45 studies, the details of each needling technique are shown in Fig. 4.

\section{Assisted body exercise}

In 32 conditions (29.6\%), patients were asked to exercise (from slight movement ranges and increase the motion gradually) their affected body parts during eyeacupuncture treatment. This applied to more than half of the conditions and related to the three musculoskeletal regions: 'lower back, lumbar spine, sacrum, and coccyx' (17, 63.0\%), 'upper shoulder and upper limbs' (6, 54.6\%) and 'cervical region' (3, 60\%).

\section{Treatment effects and side effects}

Of the 18 studies $(22.2 \%)$ [33, 35, 37, 41, 42, 49, 62, 65, $79,81,83,86-88,91,99,102,107]$ reporting outcomes on adverse events, seven studies $[37,49,65,79,83,88$, 91] found no adverse events, and four studies [35, 62, 81, 87] reported patients having slight bleeding when the needle was withdrawn. The remaining seven studies reported adverse events from eye acupuncture as well as events from other interventions during the treatment, which are shown in Table 1 . The effects following an adverse event in those receiving acupuncture were reported to have disappeared after rest. Follow-ups were reported in 15 (18.5\%) studies, with follow up periods ranging from 2 days to 12 months in eight of the case series and 3 months to 6 months in seven RCTs.

In total, 77 studies reported an overall response rate (ORR) $(87-100 \%$, median $=96.7 \%)$. ORR stands for the sum of cure rate, significant effective rate, and improvement rate, however, since the definitions of ORR varied from diseases and studies, further analysis on ORR was not feasible. All studies reported a positive result for the eye acupuncture intervention, while two three-arm RCTs $[45,107]$ showed that a combination of eye acupuncture and body acupuncture had a higher ORR compared to

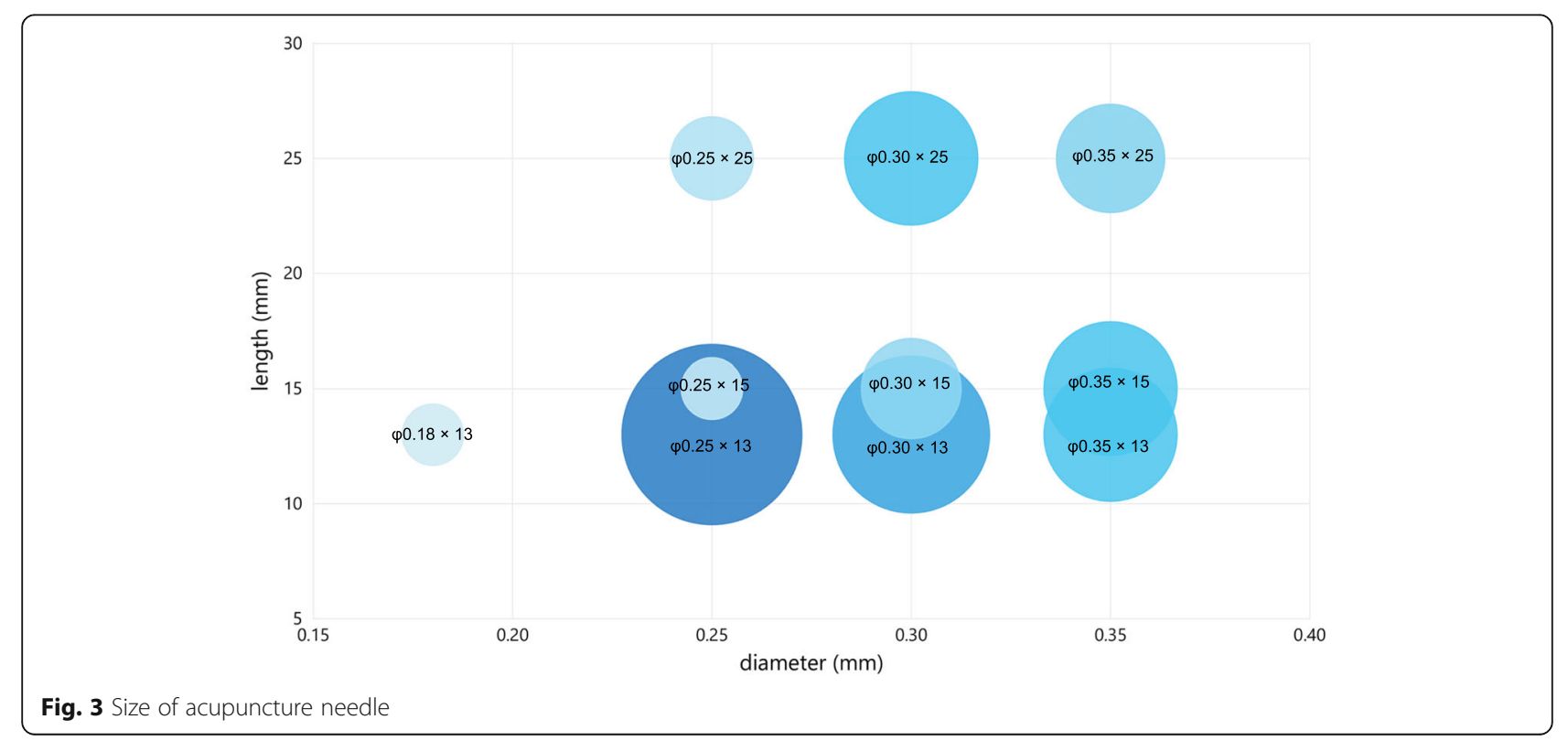




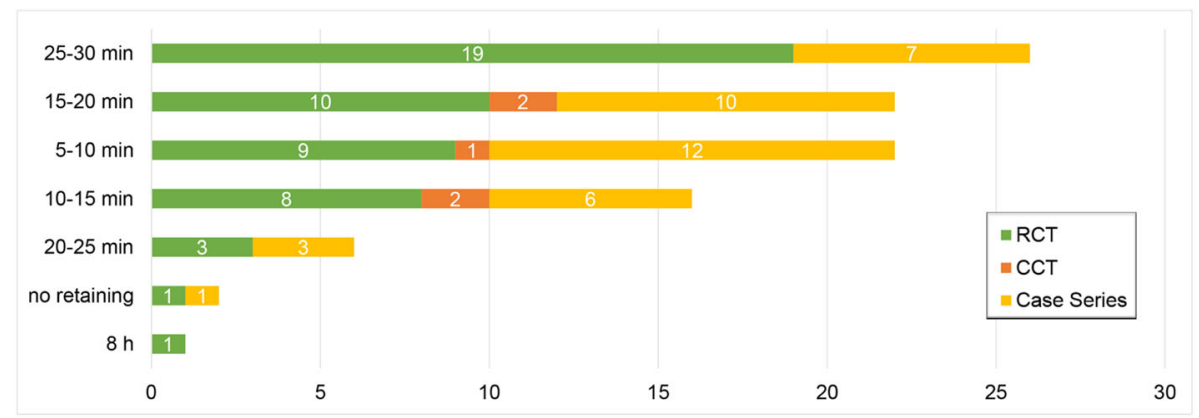

a) needle retaining time

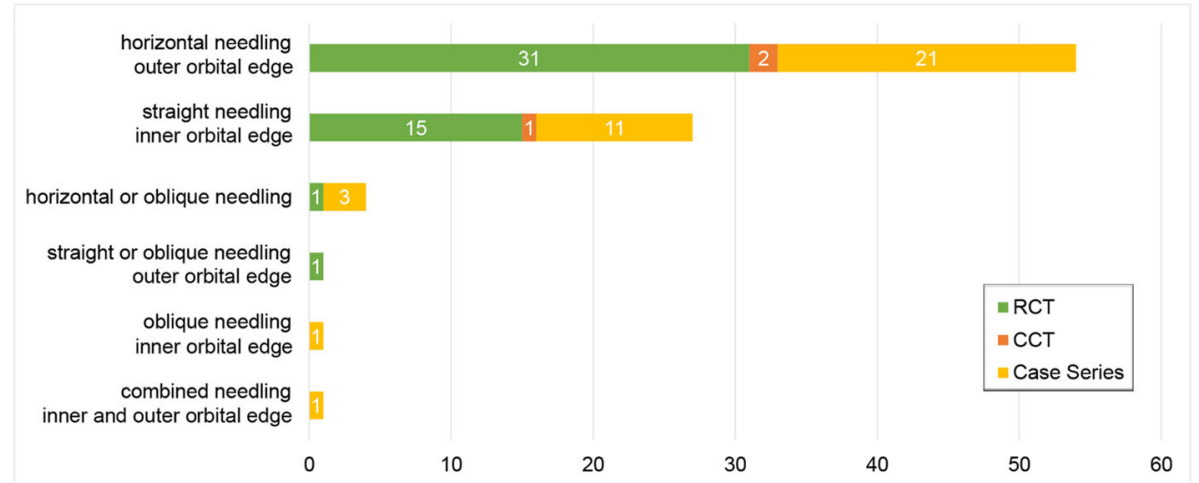

b) needle inserting approach

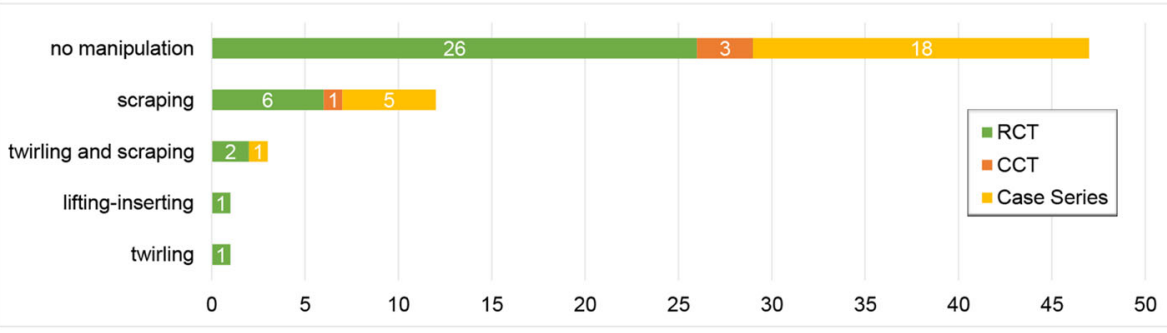

c) manipulation on needle handle

Fig. 4 Needling techniques. Abbreviations: RCTs: randomized controlled trials, CCTs: controlled clinical trials

Table 1 Details of adverse events of eye acupuncture for pain conditions

\begin{tabular}{|c|c|c|}
\hline Study (pain condition) & Groups & Adverse events \\
\hline $\begin{array}{l}\text { Zhou J } 2008 \text { [107] } \\
\text { (migraine) }\end{array}$ & $\begin{array}{l}\text { I: eye acupuncture } \\
\text { C1: eye acupuncture + body acupuncture } \\
\text { C2: body acupuncture }\end{array}$ & $\begin{array}{l}\text { I: }- \text { - } \\
\text { C1: fainting }(2,6.7 \%) \\
\text { C2: fainting }(1,3.3 \%)\end{array}$ \\
\hline $\begin{array}{l}\text { He Y } 2012[41] \\
\text { (acute goutyarthritis) }\end{array}$ & $\begin{array}{l}\text { I: eye acupuncture } \\
\text { C: body acupuncture }\end{array}$ & $\begin{array}{l}\text { I: dizziness, chest distress, nausea }(1,3.4 \%) \\
\text { C: - }\end{array}$ \\
\hline $\begin{array}{l}\text { Zhang XF } 2012 \text { [102] } \\
\text { (migraine) }\end{array}$ & $\begin{array}{l}\text { I: eye acupuncture } \\
\text { C1: eye acupuncture }+ \text { body acupuncture } \\
\text { C2: flunarizine hydrochloride }\end{array}$ & $\begin{array}{l}\text { I: fainting }(1,3.3 \%) \\
\text { C1: fainting }(1,3.3 \%) \\
\text { C2: dizziness }(1,3.3 \%)\end{array}$ \\
\hline $\begin{array}{l}\text { Zhang JY } 2008 \text { [99] } \\
\text { (acute gouty arthritis) }\end{array}$ & $\begin{array}{l}\text { I: eye acupuncture } \\
\text { C: Chinese herbal medicine }+ \text { Indomethacin }\end{array}$ & $\begin{array}{l}\text { I: abdominal discomfort }(1,3.6 \%) \\
\text { C: abdominal discomfort }(3,10.3 \%)\end{array}$ \\
\hline $\begin{array}{l}\text { Hu YL } 2011[42] \\
\text { (primary dysmenorrhea) }\end{array}$ & $\begin{array}{l}\text { I: eye acupuncture } \\
\text { C: ibuprofen }\end{array}$ & $\begin{array}{l}\text { l: - - } \\
\text { C: dizziness, headache, rash, nausea, vomit }(9,18 \%)\end{array}$ \\
\hline $\begin{array}{l}\text { Chu CL } 2015 \text { [33] } \\
\text { (menstrual headache) }\end{array}$ & $\begin{array}{l}\text { I: eye acupuncture }+ \text { Chinese herbal medicine } \\
\text { C: Chinese herbal medicine }\end{array}$ & $\begin{array}{l}\text { I: diarrhea }(3,9.4 \%) \text {; ecchymoma }(1,3.1 \%) \text {; nausea }(1,3.1 \%) \\
\text { C: fainting }(1,3.1 \%) \text {; diarrhea }(1,3.1 \%) \text {; ecchymoma }(4,12.5 \%)\end{array}$ \\
\hline $\begin{array}{l}\text { Wang Y } 2012 \text { [86] } \\
\text { (post-hemorrhoidectomy pain) }\end{array}$ & $\begin{array}{l}\text { I: eye acupuncture } \\
\text { C: bucinperazine injection }\end{array}$ & $\begin{array}{l}\text { I: analis edema }(2,4.2 \%) \text {; urinary retentron }(1,2.1 \%) \text {; nausea }(1,2.1 \%) \\
\text { C: analis edema }(1,2.1 \%) \text {; urinary retentron }(2,4.2 \%) \text {; nausea }(2,4.2 \%)\end{array}$ \\
\hline
\end{tabular}

$T$ treatment group, $C$ control group 
eye acupuncture alone. The authors explained that eye acupuncture was more effective in treating diffuse pain, while body acupuncture was more effective for treating a local pain. For treating complex pain, when two acupuncture techniques were used, outcomes were further improved. For 57 conditions (52.8\%), patients acquired an immediate analgesic effect after acupuncture, however, $38(66.7 \%)$ of these conditions were from case series studies. In the 32 pain conditions which encouraged adjunctive exercise, 26 (81.3\%) reported immediate analgesic effects. All the 81 studies presented data showing an improvement in pain relief, including the degree of pain relief, time spent without pain, relief of tenderness, reduction in persistent periods of pain, numbers of attacks, improvements in the range of motion of joints and TCM syndrome score. Apart from pain symptoms, treatment effects were also estimated by recurrences $(9$, $8.1 \%)$, changes in quality of life (including: activities of daily living $(13,11.7 \%)$, ability to work or study (20, $18.0 \%)$ and social life $(2,1.8 \%))$, and mental health (2, $1.8 \%)$. No studies reported on economic outcomes. Twelve international instruments were used in 23 studies and the Visual Analogue Scale (VAS) was the most often used. Fifty-eight papers did not use a standardized scale.

\section{Funding sources}

Seven studies [28, 49, 92, 94, 100, 105] reported funding sources and were all RCTs published in the years 2015 to 2018. All funding came from the government, including one national project, three provincial, and three municipal sources.

\section{Discussion}

\section{Main findings}

A total of 81 clinical studies using eye acupuncture were identified and an increasing publication trend from 1977 to 2019 , culminating in 45 (55.6\%) RCTs, 5 (6.2\%) CCTs, and $31(38.3 \%)$ case series, with the RCT being the main study type after 2008. The analyzed studies had a total of 7113 patients with 44 with different pain-related diseases/symptoms, representing both genders and covering all ages. The most commonly included conditions were headache, acute lumbar pain, lumbar disc herniation, shoulder-hand syndrome after stroke, periarthritis of shoulder, sciatica and dysmenorrhea. The most common needling techniques were, using small stainless-steel acupuncture needles $(\phi 0.25 \mathrm{~mm} \times 13 \mathrm{~mm})$, retained for no more than $30 \mathrm{~min}$, needling horizontal outer orbital edge and avoiding manipulating during the treatment. Additional body exercises were applied in some studies for treating musculoskeletal pain, most of which showed immediate analgesic effects.
Eye acupuncture was used alone in 44 (54.3\%) studies and in $22(40 \%)$ studies as a trial comparator, and the others used eye acupuncture combined with other treatment. Only 18 (22.22\%) studies reported on the outcome of adverse events. Outcomes were measured by multidimensional scales of pain symptoms, recurrence, quality of life, and mental health, with the VAS being the most frequently used instrument.

\section{Limitations of this analysis}

Our study has three main limitations. First, since the taxonomy of disease is developing and not fixed [110], it caused inevitable overlapping among the classification of pain. Second, all the included studies were published in China, and nearly one third (28.9\%) of the RCTs were conducted as a master's thesis, and funding was not mentioned. The quality of such studies may, therefore, be questionable, because procedures such as randomization, recruitment or measurement may not have been appropriately applied. Third, this report is unable to present information on the long-term outcomes and patients' quality of life due to lack of data on followup in the included studies.

\section{Implications for research}

The number of RCTs identified, indicate that this field already has a history and is continuing to develop. Case series will provide some evidence on effectiveness in a real-world setting but this cannot be used as evidence of effectiveness [111].

Despite the wide-ranging duration of diseases, nearly all studies reported a treatment intensity with a duration shorter than 3 months and 29 studies used one-off eye acupuncture treatment. Although the included studies have suggested that those patients with a shorter duration of the disease were more likely to receive less intense, short periods of treatment $[68,80,95,108]$ we found no evidence to confirm this assumption. The treatment intensity also depends on the type of acupuncture treatment and the patient's ability to quickly recovery [112]. If eye acupuncture therapy was acceptable and able to contribute to shorter treatment time in general, it could reduce patients' health care costs as well as social burden [113]. Unfortunately, no economic data were found in this analysis.

\section{Implications for practice}

The choice of eye-acupuncture needle and needling techniques are more important to consider in terms of safety rather than regarding the effectiveness of the intervention There is a rich blood capillary network around the orbit and withdrawing the needle there may be the possibility of slight bleeding [114]. So small needles inserted horizontally outside the orbital without any 
manipulation could lower such risks, as well as the needling time of no more than $30 \mathrm{~min}$, which is widely accepted around the world in body acupuncture.

It is known that exercise interventions could alter musculoskeletal pain memories [115], including anxiety and fear-avoidance [116]. Combining eye-acupuncture and appropriate exercise can enhance outcomes: on the one hand, eye-acupuncture can relieve pain directly; on the other hand, eye-acupuncture may enhance the efficiency of doing exercises. Since eye-acupuncture acupoints all located around the orbit, patients are able to exercise while retaining the needle.

\section{Conclusions}

Eye acupuncture has been substantially studied in China and seems to be a promising intervention used in the management of diverse pain conditions, and appeared to have no specific reported adverse events compared to other kinds of treatment. However, given the variety of study designs and reported treatment outcomes, conclusions about the evidence for eye acupuncture for specific conditions are not possible at this stage.

\section{Abbreviations}

CDC: Centers for Disease Control and Prevention; TCM: Traditional Chinese Medicine; PRISMA: Preferred Reporting Items for Systematic Reviews and Meta-Analyses; RCTs: Randomized controlled trials; CCTs: Controlled clinical trials; VAS: Visual analogue scale

\section{Supplementary Information}

The online version contains supplementary material available at https://doi. org/10.1186/s12906-021-03272-8.

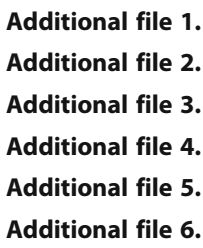

\section{Acknowledgements}

None.

\section{Authors' contributions}

YC and JL conceived the review. YC did the systematic search, study selection, and data extraction. YC and MW conducted the statistical analyses. ZL provided clinical input on pain. YC, JB and NR drafted the manuscript with interpretation and critical revision from all authors. NR edited the language. All authors reviewed and approved the final manuscript.

\section{Funding}

NR is funded by Overseas Expertise Project, Ministry of Education of China (No. G20190001122). This work was supported by the key project of National Natural Science Foundation project of China (No. 81830115).

\section{Availability of data and materials}

The data used to support the findings of this study are included within the article and the supplementary information files. Additional data will be provided on a reasonable request to the first author.

\section{Declarations}

\section{Ethics approval and consent to participate}

This study was secondary analysis based on previous published studies. Ethics approval and consent to participate is not applicable.

\section{Consent for publication}

Not applicable.

\section{Competing interests}

The authors declare that they have no competing interests.

\section{Author details}

${ }^{1}$ Centre for Evidence-Based Chinese Medicine, Beijing University of Chinese Medicine, 11 Bei San Huan Dong Lu, Chaoyang District, Beijing 100029, China. ${ }^{2}$ Institute for Complementary and Integrative Medicine, University Hospital Zurich and University of Zurich, Zurich, Switzerland. ${ }^{3}$ School of Basic Medicine, Liaoning University of Traditional Chinese Medicine, Shenyang, China. ${ }^{4}$ Institute of Health and Social Care, London South Bank University, London, UK. ${ }^{5}$ Department of Pain Management, The Second Hospital of Shandong University, Jinan, China. ${ }^{6}$ Institute of Integrated Traditional Chinese Medicine and Western Medicine, Guangzhou Medical University, Guangzhou, China.

Received: 5 November 2019 Accepted: 10 March 2021

Published online: 23 March 2021

\section{References}

1. Dowell D, Haegerich TM, Chou R. CDC guideline for prescribing opioids for chronic pain - United States, 2016. MMWR Recomm Rep. 2016;65(1):1-49. https://doi.org/10.15585/mmwr.rr6501e1.

2. $\quad$ Busse JW, Craigie S, Juurlink DN, Buckley DN, Wang L, Couban RJ, Agoritsas T, Akl EA, Carrasco-Labra A, Cooper L, Cull C, da Costa BR, Frank JW, Grant G, Iorio A, Persaud N, Stern S, Tugwell P, Vandvik PO, Guyatt GH. Guideline for opioid therapy and chronic noncancer pain. CMAJ. 2017;189(18):E659-66. https://doi.org/10.1503/cmaj.170363.

3. Upadhyay J, Maleki N, Potter J, Elman I, Rudrauf D, Knudsen J, Wallin D, Pendse G, McDonald L, Griffin M, Anderson J, Nutile L, Renshaw P, Weiss R, Becerra $L$, Borsook D. Alterations in brain structure and functional connectivity in prescription opioid-dependent patients. Brain. 2010;133(Pt 7): 2098-114. https://doi.org/10.1093/brain/awq138.

4. Vivolo-Kantor AM, Puja S, Matthew RG, Christine LM, Grant TB, Aaron K-P, Coletta MA. Vital signs: trends in emergency department visits for suspected opioid overdoses — United States, July 2016-September 2017. MMWR Morb Mortal Wkly Rep. 2018;(67):279-85.

5. Seth P, Rudd RA, Noonan RK, Haegerich TM. Quantifying the epidemic of prescription opioid overdose deaths. Am J Public Health. 2018;108(4):500-2. https://doi.org/10.2105/AJPH.2017.304265.

6. Dyer O. US opioid overdoses rise by 30\% in one year. BMJ. 2018;360:k1157.

7. Krebs EE, Gravely A, Nugent S, Jensen AC, DeRonne B, Goldsmith ES, Kroenke K, Bair MJ, Noorbaloochi S. Effect of opioid vs nonopioid medications on pain-related function in patients with chronic back pain or hip or knee osteoarthritis pain: the SPACE randomized clinical trial. JAMA. 2018;319(9):872-82. https://doi.org/10.1001/jama.2018.0899.

8. Tsagareli M. Pain medicine: general view to the problem, vol. 2; 2017.

9. Edwards E, Belard JL, Glowa J, Khalsa P, Weber W, Huntley K. DoD-NCCAM/ $\mathrm{NIH}$ workshop on acupuncture for treatment of acute pain. J Altern Complement Med. 2013:19(3):266-79.

10. Kim KH, Ryu JH, Park MR, Kim Yl, Min MK, Park YM, Kim YR, Noh SH, Kang MJ, Kim YJ, et al. Acupuncture as analgesia for non-emergent acute nonspecific neck pain, ankle sprain and primary headache in an emergency department setting: a protocol for a parallel group, randomised, controlled pilot trial. BMJ Open. 2014;4(6)

11. Yuan QL, Guo TM, Liu L, Sun F, Zhang YG. Traditional Chinese medicine for neck pain and low back pain: a systematic review and meta-analysis. PLoS One. 2015;10(2):e0117146. https://doi.org/10.1371/journal.pone.0117146.

12. Mao JJ, Kapur R. Acupuncture in primary care. Prim Care. 2010;37(1):105-17. https://doi.org/10.1016/j.pop.2009.09.010.

13. Wang PQ. Research on Peng Jing-Shan's eye-acupuncture therapy. Beijing: People's Medical Publishing House; 2015. 
14. Wang $\mathrm{PQ}$, Ju QB, Zhou HF, Wang J. Exploration on the theoretical basis of eye acupuncture therapy based on literature clinical experiment-"eyes connect with the brain and regulate the viscera". J Basic Chin Med. 2011; 17(10):1133-1134+1139.

15. Yang $T$, Wang PQ. Exploration on the specificity of acupoints of eyeacupuncture based on meridian acupoints and anatomy. Hunan J Tradit Chin Med. 2014;30(4):99-101.

16. Peng JS. Eye-acupuncture therapy. Shenyang: Liaoning Science and Technology Press; 1990.

17. Wang PQ, Wang J, Zhou HF. The effect of eye-acupuncture on nerve function defect and plasma fibrinogen level in patients with acute cerebral infarction. Shanghai J Acup Moxib. 2008;3:5-7.

18. Xu JP, Wang J, Zhou HF. The effect of eye-acupuncture on plasma endothelin in patients with acute cerebral infarction. Chin Arch Tradit Chin Med. 2006;2:365-6.

19. Liu XD, Wang L, Wang YJ, Wang Z, Chai JY, Wang DS. The effects of eyeacupuncture combined with body acupuncture on hypothalamus and colon tissue substance $\mathrm{P}$ and neural excitation peptidelreceptor expression in the diarrheal irritable bowel syndrome rat. Chin J Gerontol. 2015;35(11): 2890-3.

20. Shao $Y$, Wang $P Q$, Wang $S D, L i C H$. The effects of eye-acupuncture therapy combined with exercise therapy on VEGF protein and VEGF mRNA expression in cerebral ischemia reperfusion in rats with cerebral ischemia reperfusion. J Basic Chin Med. 2015;21(4):445-8.

21. Song SY, Wang DS, Wang YJ, Chai JY. The effect of eye-acupuncture on colon tissues and serum 5-HT and 5-HIAA in rats with irritable bowel syndrome model. Shanghai J Acup Moxib. 2010;29(6):339-41.

22. Wang J, Wang PQ. The effect of eye-acupuncture therapy on the study and memory impairment of vascular dementia rats and NOS activity in serum NO. Chin Arch Tradit Chin Med. 2007;3:485-6.

23. Xu HJ, Chen WD, Jiang HP, Liu LY. An anatomic study on acupoints area of eye acupuncture. Liaoning J Tradit Chin Med. 1989;43(1):41-3.

24. Munn Z, Peters MDJ, Stern C, Tufanaru C, MCArthur A, Aromataris E. Systematic review or scoping review? Guidance for authors when choosing between a systematic or scoping review approach. BMC Med Res Methodol. 2018:18(1):143. https://doi.org/10.1186/s12874-018-0611-x.

25. Moher D, Liberati A, Tetzlaff J, Altman DG, Group P. Preferred reporting items for systematic reviews and meta-analyses: the PRISMA statement. Int J Surg. 2010;8(5):336-41. https://doi.org/10.1016/j.jijsu.2010.02.007.

26. Tricco AC, Lillie E, Zarin W, O'Brien KK, Colquhoun H, Levac D, Moher D, Peters MDJ, Horsley T, Weeks L, Hempel S, Akl EA, Chang C, McGowan J, Stewart L, Hartling L, Aldcroft A, Wilson MG, Garritty C, Lewin S, Godfrey CM, Macdonald MT, Langlois EV, Soares-Weiser K, Moriarty J, Clifford T, Tunçalp Ö, Straus SE. PRISMA extension for scoping reviews (PRISMA-SCR): checklist and explanation. Ann Intern Med. 2018;169(7):467-73. https://doi.org/10.732 6/M18-0850.

27. Richardson WS, Wilson MC, Nishikawa J, Hayward RS. The well-built clinical question: a key to evidence-based decisions. ACP J Club. 1995;123(3):A12-3.

28. Cao YK, Liu ZD. Clinical observation of eye acupuncture combined with body acupuncture in the treatment of lumbago due to lumbar disc herniation. J Clin Acupunct Moxibustion. 2015:12:25-7.

29. Chang HZ, Lu JL, Yin SK. Report on 56 cases of acute lumbar sprain treated with eye acupuncture. Chin J Pract Nerv Dis. 2001;5:81.

30. Chang JY, Ma Q, Yue L. Clinical observation of 108 cases of acute gallbladder system pain treated by eye acupuncture. Chin Acupunct Moxibustion. 1996; 1:4.

31. Chen JG, Tang YL. 80 cases of stiff neck treated by eye acupuncture combined with nape and back finger manipulation. People's Mil Surg. 2006; 49(11):667-8.

32. Chen YF, Sun LY, Wang JM, Peng JS. Clinical observation of five kinds of pain syndrome treated with eye acupuncture. J Clin Acupunct Moxibustion. 1993;06:27-8.

33. Chu CL, Jiang XL. Chai Hu Shu Gan san combined with eye acupuncture in the treatment of 32 cases of menses headache in young women. Liaoning J Tradit Chin Med. 2015;42(5):1022-4.

34. Fu WB. Eye acupuncture as major therapy treating 136 cases of sciatica. Chin Acupunct Moxibustion. 1992;1:42.

35. Gao A. Clinical study on the treatment of irritable bowel syndrome (weakness of the spleen and stomach syndrome type) by eye acupuncture therapy. Master: Liaoning University of Traditional Chinese Medicine; 2013.
36. Gong NS. Observation on the curative effect of eye acupuncture on 98 cases of acute lumbar sprain. China's Naturopathy. 1996;06:23.

37. Guan H. The clinical effect of eye acupuncture combined with Taohong Siwu decoction in the treatment of migraine. Master: Liaoning University of Traditional Chinese Medicine; 2012.

38. Han YB, Gao YW. Eye acupuncture therapy in treating 120 cases of low back pain. Shaanxi J Tradit Chin Med. 1989:4:181.

39. He Q. Clinical observation on treatment of posterior shoulder-hand syndrome after stroke with eye acupuncture and polarized light. Master: Liaoning University of Traditional Chinese Medicine; 2014.

40. He XJ. Eye acupuncture treating 68 cases of lumbar intervertebral disc herniation. Shanghai J Acupunct Moxibustion. 2000;03:31.

41. He Y. Clinical comparative study on the treatment of acute gouty arthritis by eye acupuncture and corresponding acupoint acupuncture. Master: Guangzhou University of Traditional Chinese Medicine; 2012.

42. $\mathrm{Hu} Y \mathrm{Y}$, Lin $\mathrm{Q}, \mathrm{Li} Y$, Zheng $X M$. The effect of eye acupuncture on PGF_(2a) in plasma of primary dysmenorrhea patients. Chin Acupunct Moxibustion. 2011;08:683-6.

43. Huang QF. Clinical observation of 30 cases of sciatica treated by eye acupuncture. J Clin Acupunct Moxibustion. 1992;6:35-6.

44. Huang XJ, Qin HJ, Xin J, Wang LL. Eye acupuncture combined with fu acupuncture in treating 170 cases of military training injuries. People's Mil Surg. 2009;01:68

45. Huang XJ, Xin J, Wang LL, Qin HJ. Clinical observation on the treatment of injury pain syndrome by eye acupuncture combined with fu acupuncture. Chin J Pract Chin Mod Med. 2008;6.

46. Jiang $L B, Y u X A$. Eye acupuncture therapy in treating 35 cases of traumatic low back pain. Chin Acupunct Moxibustion. 1996;01:33.

47. Jin L. Clinical efficacy of eye acupuncture combined with traditional Chinese medicine in the treatment of headache in hyperactivity of liver-yang type. Master: Liaoning University of Traditional Chinese Medicine; 2011.

48. Jing $\mathrm{SQ}$, Wang $\mathrm{PQ}$. The treatment of headache by Peng's eye acupuncture. Shanghai J Acupunct Moxibustion. 2015;11:1038-9.

49. Ju QB, Wang PQ. Clinical observation of analgesic technique for treating shoulder hand syndrome after stroke with eye acupuncture and ironing. J Basic Chin Med. 2016:(07):960-961+996.

50. Ju YD, Ju YR, Chen SM. Acupuncture and medical treatment for 60 cases with periarthritis of shoulder. J Changchun Univ Chin Med. 2009;1:110-1.

51. Ju YR. The clinical application of eye acupuncture combined with body acupuncture and its experience. J Jinzhou Med Univ. 1999;06:54-5.

52. Leng JQ, Lin Q, Li Y, Hu YL. The effect of eye acupuncture on hemorheology of primary dysmenorrhea patients. Clin J Chin Medi. 2012;15: 4-6.

53. Li HA. Eye acupuncture treatment of 52 cases with periarthritis of shoulder. Chin Acupunct Moxibustion. 1990;04:26.

54. Li MM. Study on analgesic effect of eye acupuncture on pain of lumbar spine disease. Chin Manipulation Rehabil Med. 2014;5(4):71-2.

55. Li MP, Wang QL. Clinical observation of 23 cases of sciatica treated by eye acupuncture. Chin Community Doctors. 1990;4:37.

56. Li YX. Eye acupuncture treatment of 110 cases of shoulder pain. Liaoning J Tradit Chin Med. 1986;1:29.

57. Li ZP, Lun X, Rong L. Eye acupuncture combined with acupoint injection for 40 cases of sciatica. Shanghai J Acupunct Moxibustion. 1996;1:156-7.

58. Lin B. Clinical observation of 50 cases with stiff neck treated by eye acupuncture. Fujian J Tradit Chin Med. 1997;06:25.

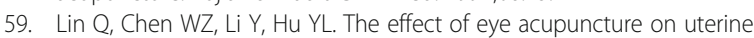
artery blood flow of primary dysmenorrhea patients. Shanghai J Acupunct Moxibustion. 2012;12:885-7.

60. Lin $\mathrm{Q}$, Chen XT, Chen WZ. Observation on the curative effect of eye acupuncture on cholelithiasis induced biliary colic. Clin J Chin Med. 2013;19: $36-8$

61. Lin Q, Hu YL, Han CW, Li Y. Clinical observation on eye acupuncture for 90 cases of renal and ureteral colic caused by ureteral calculi. Shanghai J Acupunct Moxibustion. 2007;9:12-3.

62. Liu J. Study on the therapeutic effect evaluation and mechanism of the treatment of patients with irritable bowel syndrome in Ganyu Chengpi type. Master: Liaoning University of Traditional Chinese Medicine; 2013.

63. Liu YQ, Xu J, Yuan SH, Wen Q, Guo HW. Clinical observation of 37 cases of acute lumbar sprain treated with eye acupuncture. J Clin Acupunct Moxibustion. 1999;03:58-9. 
64. Ma BD. Clinical observation of 46 cases of sicca syndrome treated by eye acupuncture. In: The sixteenth national conference on rheumatism by China Association of Chinese Medicine. Huangshan; 2012. p. 2.

65. Mao L, Zhang W, Zhang MB. A randomized parallel controlled study on the treatment of migraine with eye acupuncture combined with scalp acupuncture. J Pract Tradit Chin Intern Med. 2014;07:148-50.

66. Meng QL. Eye acupuncture combined with scalp acupuncture treatment for 94 cases of migraine. J Clin Acupunct Moxibustion. 1990;6(3):20.

67. Ning WD. The experience of eye acupuncture with Xiaojie pills for the treatment of mammary lump. J Liaoning Univ Tradit Chin Med. 2007;02: 106-7.

68. Niu WM. Observation on the effect of eye acupuncture on 100 cases of lumbago. J Ningxia Medi Univ. 1995;4:368.

69. Qin HJ. Treating 36 cases of herpes zostertreated by combination of eye acupuncture, body acupuncture and medicine. China Med Herald. 2011;31:121-2.

70. Qin HJ. 23 cases of trigeminal neuralgia treated by eye acupuncture combined with acupuncture and medicine. China Mod Med. 2013;5:111-2.

71. Song MX. Report on 124 cases of acute abdominal pain treated with eye acupuncture. J Emerg Tradit Chin Med. 1995;03:120-5.

72. Sui YJ, Wang J. Eye acupuncture combined with Yangxin Kuanxiongtang treating 65 cases of heart plant nerve function disorder. Chin J Tradit Chin Med. 2007;5(2):54-5

73. Tang SS. Clinical observation of 31 cases of trigeminal neuralgia treated by eye acupuncture. Nei Mongol J Tradit Chin Med. 1999;3:31.

74. Tang SS. Clinical observation of 108 cases of biliary colic treated by eye acupuncture. J Guangxi Univ Chin Med. 2000;04:41-2.

75. Tian $J$. The effect of eye acupuncture on the clinical efficacy and psychological factors of patients with irritable bowel syndrome. Master: Liaoning University of Traditional Chinese Medicine; 2012.

76. Tong $Y$, Wang $P Q$. Observation on the curative effect of eye acupuncture combined with thunder and fire moxibustion on 60 cases of shoulder and hand syndrome after stroke. Hunan J Tradit Chin Med. 2017;05:102-3.

77. Tu GQ, Zeng LQ. Clinical study on treatment of lumbar spinal stenosis with eye acupuncture and Tuina. Clin J Tradit Chin Med. 2017;12:2101-3.

78. Wang JH, Yang HO, Shuai KP, Pan Q, Mai DJ. Clinical observation of 122 cases of biliary colic treated by eye acupuncture. Chin Acupunct Moxibustion. 1989;02:27-8.

79. Wang KM. Clinical observation of acupuncture for the treatment of blood deficiency liver depression type tension headache. Master: Liaoning University of Traditional Chinese Medicine; 2011.

80. Wang ML, Li J, Jiang C. Eye acupuncture for dysmenorrhea. J Clin Acupunct Moxibustion. 1991;03:39-40.

81. Wang PQ, Chen SN, Liu YD, Chen XY, Wang J. Clinical study on 60 cases of diarrheal irritable bowel syndrome treated by eye acupuncture. J Tradit Chin Med. 2011;14:1203-6.

82. Wang Y. Study on the treatment of vascular headache by eye acupuncture and holographic therapy. J Pract Tradit Chin Intern Med. 1999;02:49.

83. Wang Y. Observation on clinical effect of eye acupuncture on headache in the type of hyperactivity of liver Yang. Master: Liaoning University of Traditional Chinese Medicine; 2016

84. Wang $Y$, Wang $P Q$. Eye acupuncture combined with traditional Chinese medicine in the treatment of migraine: a randomized controlled observation. J Pract Tradit Chin Intern Med. 2013;1.

85. Wang Y, Wang PQ. Clinical observation on 80 cases of blood stasis headache treated by eye acupuncture. J Pract Tradit Chin Intern Med. 2016:04:96-8.

86. Wang Y, Ye GA, Zhou H. Eye acupuncture for mixed hemorrhoids postoperative pain. Guide China Med. 2012;31:595-6

87. Wang YJ, Wen TY, Qiu WJ. A comparative study on the treatment of lumbar intervertebral disc herniation by eye acupuncture and conventional acupuncture. Rheum Arthritis. 2015;01:32-4.

88. Wang ZC. Observation on the curative effect of eye acupuncture therapy combined with rehabilitation training on shoulder and hand syndrome after stroke. Master: Liaoning University of Traditional Chinese Medicine; 2014.

89. Xue AG. Treatment of 36 cases of lumbar intervertebral disc herniation by acupuncture. In: The ninth academic seminar of guangdong acupuncture society. Guangzhou; 2004. p. 2.

90. Yan H, Zou KJ. Treatment of 52 cases of cervical spondylosis with eye acupuncture. Chin Acupunct Moxibustion. 1996;12:12.

91. Yang Y. Clinical observation of 60 cases of herpes zoster treated by eye needle and "hooping stitch" combined with semiconductor laser. Master: Hubei University of Chinese Medicine; 2013.
92. Yang ZB, Liu D, Chang YS, Qian H, Jia L. The clinical study of eye acupuncture and rood physical technique in the treatment of hemiplegic shoulder pain after stroke. Chin Med Mod Distance Educ China. 2015;19:77-9.

93. Yin SK. Eye acupuncture treatment of 90 cases of periarthritis of shoulder. Chin Acupunct Moxibustion. 1995;01:46.

94. Yuan $\mathrm{HL}$, Liang LB, Huang JP, Li JH. Effect of acupuncture on forearm response points, combined with eye acupuncture and physiotherapy on acute stage of lumbar disc herniation. China Pract Med. 2017;17:1-3.

95. Zhan DQ, Li FL. Report on 102 cases of backache treated by eye acupuncture. J Clin Acupunct Moxibustion. 2000;4:34-5.

96. Zhang CM, Jiang YS. Clinical observation on the treatment of lumbar intervertebral disc herniation by eye acupuncture. Liaoning J Tradit Chin Med. 2004;11:956.

97. Zhang CY. Treatment of acute lumbar sprain with eye acupuncture. Heilongjiang J Tradit Chin Med. 1994;06:38.

98. Zhang HP. Eye acupuncture treatment on 92 cases of functional headache. Shaanxi J Tradit Chin Med. 1998:11:512.

99. Zhang JY. Clinical study of eye acupuncture therapy on acute gouty arthritis. Master: Guangzhou University of Traditional Chinese Medicine; 2008.

100. Zhang M, Wang Y. Treatment of achalasia of cardia with eye acupuncture combined with thunder and fire moxibustion. J Changchun Univ Chin Med. 2017:06:945-8.

101. Zhang O, Tian WZ. Treatment of primary dysmenorrhea by eye acupuncture therapy. J Clin Acupunct Moxibustion. 2008;01:25-6.

102. Zhang XF. Clinical study of eye acupuncture therapy for the treatment of headache in hyperactivity of liver-yang type. Master: Liaoning University of Traditional Chinese Medicine; 2012.

103. Zhao BM. Eye acupuncture combined with traditional Chinese medicine to treat thromboangiitis obliterans. Chin Acupunct Moxibustion. 1994;(S1):81-83+495.

104. Zhao HY. Eye acupuncture combined with Canggui Tanxue technic for 40 cases with periarthritis of shoulder. Chin Med Mod Distance Educ China. 2012;09:34-5

105. Zhao $X$, Wang PQ. Observation on the therapeutic effect of eye acupuncture and body acupuncture on thalamic pain. Shanghai J Acupunct Moxibustion. 2016;7:805-7.

106. Zheng KL. Clinical observation on 35 cases of stiff neck treated by massage and eye acupuncture. Hebei J Tradit Chin Med. 2013;1:83-4.

107. Zhou J. Clinical study on the treatment of migraine using eye acupuncture combined with body acupuncture. Master: Liaoning University of Traditional Chinese Medicine; 2008

108. Zhu FS, Cao LH. Clinical observation of 100 cases of headache treated by eye acupuncture. J Clin Acupunct Moxibustion. 1992;01:38.

109. Merskey H, Bogduk N. Classification of chronic pain. 2nd ed. Seattle: IASP Press; 1994.

110. Treede RD, Rief W, Barke A, Aziz Q, Bennett MI, Benoliel R, Cohen M, Evers S, Finnerup NB, First MB, Giamberardino MA, Kaasa S, Kosek E, Lavand'homme P, Nicholas M, Perrot S, Scholz J, Schug S, Smith BH, Svensson P, Vlaeyen JWS, Wang SJ. A classification of chronic pain for ICD-11. Pain. 2015;156(6): 1003-7. https://doi.org/10.1097/j.pain.0000000000000160.

111. Sayre JW, Toklu HZ, Ye F, Mazza J, Yale S. Case reports, case series - from clinical practice to evidence-based medicine in graduate medical education. Cureus. 2017;9(8):e1546. https://doi.org/10.7759/cureus.1546.

112. van der Glas HW, van Grootel RJ. The index 'treatment duration control' for enabling randomized controlled trials with variation in duration of treatment of chronic pain patients. BMC Med Res Methodol. 2013;13(1):123. https://doi.org/10.1186/1471-2288-13-123.

113. Kim HS, Choi JW, Chang SH, Lee KS, Oh JY. Treatment duration and cost of work-related low Back pain in Korea. J Korean Med Sci. 2005;20(1):127-31. https://doi.org/10.3346/jkms.2005.20.1.127.

114. Shang JS, Li YD, Zhang J. Measures prevent bleeding in eye-acupuncture therapy. J Clin Acup Mox. 1994;3:34-5.

115. Nijs J, Lluch Girbes E, Lundberg M, Malfliet A, Sterling M. Exercise therapy for chronic musculoskeletal pain: innovation by altering pain memories. Man Ther. 2015;20(1):216-20. https://doi.org/10.1016/j.math.2014.07.004.

116. Lucchetti G, Oliveira AB, Mercante JP, Peres MF. Anxiety and fear-avoidance in musculoskeletal pain. Curr Pain Headache Rep. 2012;16(5):399-406. https://doi.org/10.1007/s11916-012-0286-7.

\section{Publisher's Note}

Springer Nature remains neutral with regard to jurisdictional claims in published maps and institutional affiliations. 